Check for updates

Cite this: RSC Adv., 2019, 9, 24904

\title{
Precision synthesis of 3-substituted urushiol analogues and the realization of their urushiol-like performance $\uparrow$
}

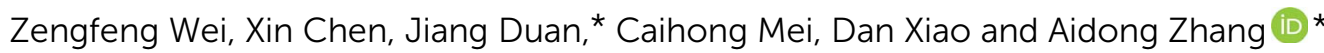

Urushiol is a resource-limited natural coating material with diverse applications; however, the synthesis of urushiol analogues and the realization of their urushiol-like performance remain challenging. Herein, four urushiol analogues, namely, 3-((4-alkenoylpiperazin-1-yl)methyl)catechols with the precise 3-substitution pattern on a catechol as that found in urushiol were synthesized by employing the Mannich reaction of catechol with formaldehyde and $\mathrm{N}$-Boc-piperazine as the key step in a two-step route. By using optimization, the advantages of convenience in operation, cost-effectiveness, and scalability could be obtained. The electropolymerization of these analogues on copper was found to be practical due to their higher aerobic stability than urushiol, affording robust coatings with desirable hardness, adhesion strength, hydrophobicity, and thermal stability. Furthermore, the coatings exhibited effective corrosion protection on copper with initial anticorrosion efficiency up to $99.9 \%$ and comparatively higher efficiency (more than 97\%) after 4 weeks of immersion in $3.5 \mathrm{wt} \% \mathrm{NaCl}$ solution. The evidence from the electrochemical and infrared spectroscopic characterization data revealed that the electropolymerization process mechanically involved the free radical coupling of phenoxyl radicals to themselves and to the $\mathrm{C}=\mathrm{C}$ bonds in the side chain, forming a robust crosslinking coating. This work paves a way for the synthesis of high-performance urushiol analogues with potential applications as metal protection materials.

Received 2nd July 2019

Accepted 24th July 2019

DOI: 10.1039/c9ra04981a

rsc.li/rsc-advances
The synthesis of natural urushiol has proven to be challenging (Scheme 1b). ${ }^{11,12}$ With 3,4-dihydroxybenzaldehyde as the raw material, Dawson et al. developed a five-step procedure, involving hydroxyl protection, addition reaction, dehydration, catalytic hydrogenation, and subsequent deprotection, to yield urushiols containing one or no $\mathrm{C}=\mathrm{C}$ bond in the alkenyl side chain. ${ }^{11}$ To verify the structure of the extractants from the lacquer tree, $\mathrm{Lu}$ and co-workers also designed an elaborate fivestep route for the synthesis of $\omega$-phenylalkylcatechols as urushiols using 1,10-decanediol and 1,2-dimethoxybenzene as the raw materials. ${ }^{12}$ These syntheses employed lengthy routes, expensive reagents, and harsh reaction conditions, making their actual applications difficult. As an alternative strategy to the synthesis of urushiol, the design and synthesis of urushiol analogues have been extensively investigated. For example, Kobayashi and co-workers reported a one-step process to obtain urushiol analogues by the lipase-catalyzed esterification of 3,4dihydroxybenzyl alcohol with unsaturated fatty acids. ${ }^{13}$ They also used eugenol (4-allyl-2-methoxyphenol) as the starting material after organosilane protection, thiol-ene click reaction, and deprotection to obtain a number of urushiol analogues with different alkyl chain lengths. ${ }^{14}$ In addition, there are many reports on the synthesis of the multi-component mixtures of urushiol analogues. Tsujimoto and colleagues used 6-hydroxy1-naphthoic acid and linseed oil or fish oil and employed

phenolic hydroxyl protection, acyl chlorination, and
Key Laboratory of Pesticide \& Chemical Biology of the Ministry of Education, College of Chemistry, Central China Normal University, Wuhan 430079, P. R. China. E-mail: adzhang@mail.ccnu.edu.cn; duanj@mail.ccnu.edu.cn

$\dagger$ Electronic supplementary information (ESI) available. See DOI: 10.1039/c9ra04981a 
a. Natural urushiol with a typical composition<smiles>[R]c1cccc(O)c1O</smiles><smiles>[R]CCCC=CCC=CC=CC</smiles><smiles>CCCCC=CCCCCCC</smiles>
$\mathrm{X}_{6}=$ $\mathrm{X}_{6}=$ 疗<smiles>CCCC=CC=CCC=CCCC</smiles>
others

b. Synthesized urushiol and analogues<smiles>CCCCCCCc1cccc(O)c1O</smiles>

Ref. 11

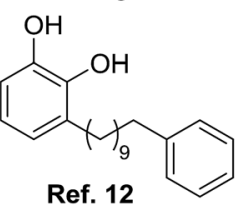

Ref. 12
$55.4 w t \%$

$15.0 \mathrm{wt} \%$

$7.4 \mathrm{wt} \%$

$6.5 \mathrm{wt} \%$

$4.5 \mathrm{wt} \%$

$4.4 \mathrm{wt} \%$

$6.7 \mathrm{wt} \%$

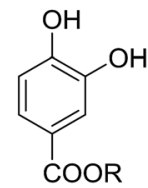

Ref. 13<smiles>[R]SCCc1ccc(O)c(O)c1</smiles>

c. This work

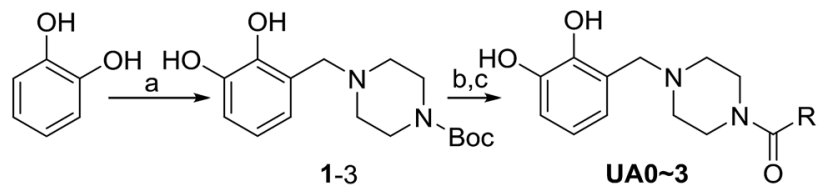

Scheme 1 Composition of natural urushiol, structures of synthesized urushiol and urushiol analogues, and synthesis route for urushiol analogues used in this work.

esterification to synthesize a mixture of urushiol analogues. ${ }^{15}$ Zhou et al. reported the synthesis of a multi-component mixture of urushiol analogues by the photoinitiated radical reaction of catechol with the alkenyl chains of tung oil. ${ }^{\mathbf{1 6}}$ To the best of our knowledge, all these reported urushiol analogues are 4substituted catechols, instead of the 3-substitution pattern inherent in urushiol. Nevertheless, these synthesis methods for urushiol analogues have effectively exploited the naturally occurring abundant triglycerides, providing the potential for large-scale synthesis and applications of urushiol analogues. Considering that the substitution pattern on catechol may have important influences on their properties, to synthesize urushiol analogues with the precise 3-substitution on catechol is highly desirable in realizing the natural urushiol-like performance.

Closely related to the application of urushiol analogues, their curing methods are also an important topic of interest, because the curing conditions of urushiol, where endogenous laccase is necessary, are usually ineffective toward analogues due to the specificity of laccase catalysis. ${ }^{17}$ To cure urushiol analogues, various oxidants, transition metal catalysts, and even catalase for generating the $\mathrm{H}_{2} \mathrm{O}_{2}$ oxidant, have been attempted. For example, the $\mathrm{Fe}(\mathrm{III})$-salen complex or cobalt naphthenate was reported to cure 3,4-dihydroxybenzyl-alcohol-based urushiol analogues that have 2 or $3 \mathrm{C}=\mathrm{C}$ bonds in the side chain. ${ }^{18}$ The $\mathrm{Fe}(\mathrm{III})$-salen complex, as well as catalase, was also able to polymerize cardanol, a natural product of phenol with a 3substituted unsaturated aliphatic chain as the urushiol analogue. ${ }^{19}$ On the other hand, to facilitate the curing of natural urushiol, electrochemical methods (e.g., potentiostatic electropolymerization) have been explored, but no performance of the coating has been reported; $;^{20}$ in particular, no such method has been applied to the curing of urushiol analogues. If the electropolymerization method could be used for the curing of urushiol analogues, it would have advantages such as operational convenience, easy control over the coating thickness, and applicability to different shapes of metal surfaces. ${ }^{21}$

In this work, four urushiol analogues, namely, 3-((4alkenoylpiperazin-1-yl)methyl)catechols with a precise 3substitution pattern on catechol as that of urushiol, were synthesized by exploiting the cheap and readily available catechol, formaldehyde, $N$-Boc-piperazine, and fatty acids as the raw materials, as well as the classical and high-yield Mannich reaction and amidation reaction (Scheme 1c). It should be noted that in order to address the main issue involving the substitution pattern of urushiol analogues, commercially available unsaturated fatty acids were used in the synthesis, all of which contain $\mathrm{C}=\mathrm{C}$ bonds in the cis configuration. Furthermore, an electropolymerization protocol was developed to cure these urushiol analogues on copper; in addition, their proportional mixture (UAm) with a composition ratio similar to natural urushiol, as well as urushiol itself, for effecting a comparison. The cured coating structure and morphologies and the anticorrosion performance for copper in $3.5 \mathrm{wt} \% \mathrm{NaCl}$ were investigated and discussed.

\section{Results and discussion}

\section{Optimization of the Mannich reaction and purification}

A two-step procedure was developed for the synthesis of urushiol analogues, including the Mannich reaction of catechol with formaldehyde and $N$-Boc-piperazine and deprotection, in addition to amidation with various fatty acids bearing $0-3 \mathrm{C}=\mathrm{C}$ bonds, such as stearic acid, oleic acid, linoleic acid, and $\alpha$ linolenic acid (Scheme 1c). The Mannich reaction to yield the intermediate 3-((4-Boc-piperazin-1-yl)methyl)catechol (1-3) is the key to the success of this two-step procedure. Due to the directing role of the two ortho-hydroxyls, catechol has two active sites for the Mannich electrophilic substitution; hence, a mixture of 3- and 4-substituted catechols would be obtained. The 4-substituted catechol is an unwanted byproduct for the purpose of this study since urushiol mainly consists of 3-alkenylcatechols (Scheme 1a). To this end, the reaction conditions of the Mannich reaction were optimized with the expectation to minimize the yield of 4-substituted catechols.

In our previous work, water was used as the reaction medium for the Mannich reaction of catechol with formaldehyde and diethanolamine to yield 4-diethanolaminomethyl catechol. ${ }^{22}$ To obtain the 3-substituted intermediate 1-3, $N$-Boc-piperazine instead of diethanolamine was used as the partner in the Mannich reaction. Due to the poor solubility of $\mathrm{N}$-Bocpiperazine in water, a number of organic solvents and $\mathrm{CH}_{3} \mathrm{OH} / \mathrm{H}_{2} \mathrm{O}$ mixture were explored, and the results are listed in 
Table 1. The reaction was first conducted using $\mathrm{CH}_{3} \mathrm{OH}$ as the medium at $40{ }^{\circ} \mathrm{C}$ under $\mathrm{N}_{2}$ and continued until there were no obvious changes in the product composition as determined by thin-layer chromatography ( $c a .4 \mathrm{~h}$ ), resulting in a conversion rate of $85 \%$ for catechol and the generation of 1-3 and 4substituted byproduct 1-4 in yields of 61 and 10\%, respectively (Table 1, entry 1) (conversion rate determination and product isolation are discussed below). Then, the other organic solvents, namely, 1,4-dioxane, $\mathrm{CH}_{3} \mathrm{CN}$, THF, and isopropanol, were examined. The reaction in 1,4-dioxane for $6 \mathrm{~h}$ afforded a catechol conversion rate of $86 \%$, as well as 1-3 and 1-4 in yields of 54 and $10 \%$, respectively (entry 2). In $\mathrm{CH}_{3} \mathrm{CN}$, THF, or isopropanol, the reaction yielded similar results to those in $\mathrm{CH}_{3} \mathrm{OH}$ and 1,4-dioxane (entries 3-5). When the mixture of $1: 1$ (v/v) $\mathrm{CH}_{3} \mathrm{OH} / \mathrm{H}_{2} \mathrm{O}$ was used as the medium, the reaction at $25{ }^{\circ} \mathrm{C}$ for $4 \mathrm{~h}$ afforded a low conversion rate of $65 \%$ for catechol, as well as 1-3 and 1-4 in yields of 23 and 36\%, respectively (entry 6). Fortunately, when the temperature was raised to $40{ }^{\circ} \mathrm{C}$ for $4 \mathrm{~h}$, a conversion rate of up to $88 \%$ and the highest yield of $76 \%$ for 1-3 were achieved, where only a trace of 1-4 was generated (entry 7). Although the highest conversion of catechol (91\%) was reached at $60{ }^{\circ} \mathrm{C}$ for $4 \mathrm{~h}$, the yield of 1-3 inversely decreased to $68 \%$ (entry 8 ). In addition, conducting the reaction without $\mathrm{N}_{2}$ protection always resulted in decreased yields.

Hence, the optimal reaction conditions were determined as a mixture of $\mathrm{CH}_{3} \mathrm{OH} / \mathrm{H}_{2} \mathrm{O}$ in a volumetric ratio of $1: 1$ as the medium at $40{ }^{\circ} \mathrm{C}$ for $4 \mathrm{~h}$. The obtained results suggest that the presence of $\mathrm{H}_{2} \mathrm{O}$ in the medium is important and it remarkably improved the 3-position selectivity. In the mechanism of this three-component Mannich reaction, an iminium cation is first generated $^{23}$ from the reaction between the aldehyde and amine; further, due to its highly positive charge, high dielectric water as the medium is more favorable to its formation than common solvents such as $\mathrm{CH}_{3} \mathrm{OH}$, THF, etc., among which $\mathrm{CH}_{3} \mathrm{OH}$ is relatively better. To balance the requirements of simultaneously high dielectricity and solubility for the reaction, the mixture of
$\mathrm{CH}_{3} \mathrm{OH} / \mathrm{H}_{2} \mathrm{O}$ in a volumetric ratio of $1: 1$ as the medium was considered suitable. On the other hand, the reaction in the $\mathrm{CH}_{3} \mathrm{OH} / \mathrm{H}_{2} \mathrm{O}$ medium performed better at $40{ }^{\circ} \mathrm{C}$ (entry 7 ) than that at $25{ }^{\circ} \mathrm{C}$ (entry 6 ), because the former afforded 1-3 in 76\% yield and 1-4 in trace amounts, while the latter afforded 1-3 and 1-4 in yields of 23 and 36\%, respectively. This regioselectivity of the Mannich reaction favored at a higher reaction temperature suggests the kinetic control process in the formation of 1-3.

During the optimization of the reaction conditions, separating the desired product 1-3 from the byproduct 1-4 was firstly attempted using column chromatography. However, due to the strong adsorption of 1-3 and 1-4 on silica gel, low yields were obtained. To improve the yields, a pH-controlled extractionrecrystallization method, which was developed in our previous work, $^{22}$ was found to be fairly suitable. Briefly, the reaction solution mixture was first stripped of $\mathrm{CH}_{3} \mathrm{OH}$ and adjusted to $\mathrm{pH}$ 2 , followed by catechol recovery by EtOAc extraction for calculating the reaction conversion rate; however, the mixture of 1-3 and 1-4 as ammonium salts remained in the aqueous phase. Next, the aqueous phase was adjusted to $\mathrm{pH} 8$, converting the products to their zwitterionic forms, which made them less soluble in water and extractable with EtOAc. This solubility reduction in $\mathrm{H}_{2} \mathrm{O}$ for the zwitterionic forms is analogous to the purification process of amino acids. ${ }^{24}$ We speculated that the extracted product mixture in EtOAc might get converted into the non-dissociated neutral states, thereby resulting in high solubility. After the removal of the solvent, the mixture was recrystallized in $\mathrm{CH}_{3} \mathrm{CN}$ to afford the byproduct 1-4 as a crystal, while the filtrate yielded 1-3 as a liquid after the removal of $\mathrm{CH}_{3} \mathrm{CN}$.

Following the synthesis of 1-3, a hydrolysis reaction ${ }^{25}$ was conducted using $37 \% \mathrm{HCl}$ in EtOAc at room temperature, giving the intermediate 3-(piperazin-1-ylmethyl)catechol (2). The hydrolysis was complete in $4 \mathrm{~h}$; thereafter, a suitable amount of $\mathrm{H}_{2} \mathrm{O}$ was added, and the pH-controlled extraction-recrystallization was repeated. In this circumstance, after the aqueous phase was adjusted to $\mathrm{pH}$, extraction with EtOAc and rotary

Table 1 Optimization of Mannich reaction conditions

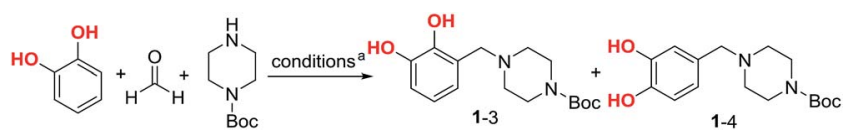

\begin{tabular}{llllll}
\hline Entry & Solvent & Temperature $\left({ }^{\circ} \mathrm{C}\right)$ & Time $(\mathrm{h})$ & Conversion $^{b}(\%)$ & Yield of $\mathbf{1 - 3}-\mathbf{4}^{c}(\%)$ \\
\hline 1 & Methanol & 40 & 4 & 85 & $61 / 10$ \\
2 & 1,4-Dioxane & 40 & 6 & 86 & $54 / 10$ \\
3 & Acetonitrile & 40 & 6 & 88 & $59 / 20$ \\
4 & THF & 40 & 6 & 70 & $31 / 15$ \\
5 & Isopropanol & 40 & 4 & 65 & $23 / 36$ \\
6 & Methanol/ $\mathrm{H}_{2} \mathrm{O}$ & 25 & 4 & 88 & $76 /$ trace \\
7 & Methanol/ $\mathrm{H}_{2} \mathrm{O}$ & 40 & 4 & 91 & $68 /$ trace
\end{tabular}

${ }^{a}$ Reaction conditions: catechol $(0.02 \mathrm{~mol}), \mathrm{N}$-Boc-piperazine $(0.02 \mathrm{~mol})$, formaldehyde ( $0.02 \mathrm{~mol}, 37 \mathrm{wt} \%$ aqueous $)$, solvent $(30 \mathrm{~mL}), \mathrm{N}_{2}$ atmosphere.

${ }^{b}$ The conversion rate of catechol was calculated based on the recovered amount of catechol. ${ }^{c}$ Yield of isolated product. 
drying afforded a residue, which was recrystallized in $\mathrm{CH}_{3} \mathrm{CN}$ to afford 2 as a yellow crystal in high yield (96\%).

Owing to the high yield of 1-3 and a trace amount of 1-4 produced in the optimized Mannich reaction, as well as the fact that 2 is a solid, the two reactions could be combined without using column chromatography to purify 1-3, not only avoiding the loss resulting from the adsorption on silica gel, but also simplifying the post-synthesis purification process. Hence, after the Mannich reaction, $\mathrm{CH}_{3} \mathrm{OH}$ was removed, and $37 \% \mathrm{HCl}$ and EtOAc were added. Further, the reaction mixture was stirred for $4 \mathrm{~h}$ at room temperature and then subjected to the $\mathrm{pH}$ controlled extraction-recrystallization procedure, directly affording the desired intermediate 2 with sufficient purity, as confirmed by NMR, required for the subsequent synthesis of urushiol analogues. This simplification made the synthesis of 2 expedient and suitable to be scaled up. In this case, a 4 -fold synthesis of 2 was carried out with the simplified procedure using $17.6 \mathrm{~g}$ catechol (160 $\mathrm{mmol})$ and other reactants, furnishing $24.3 \mathrm{~g}$ of 2 at a total yield of $73 \%$ for the two combined steps.

\section{Synthesis and characterization of urushiol analogues}

The second step in the synthesis procedure was the amidation reaction of intermediate 2 with equimolar fatty acids bearing 0 $3 \mathrm{C}=\mathrm{C}$ bonds, including stearic acid, oleic acid, linoleic acid, and $\alpha$-linolenic acid, affording the respective four urushiol analogues (UA0 $\sim 3$ ). The amidation reaction was carried out using the coupling agents of $\mathrm{EDC} \cdot \mathrm{HCl}$ and $\mathrm{NHS}$ in $\mathrm{CH}_{2} \mathrm{Cl}_{2}$ and the product was purified by flash column chromatography on silica with EtOAc/petroleum ether as the eluent initially at the ratio of $1: 4(\mathrm{v} / \mathrm{v})$ and then of $1: 2$, affording UA0 $\sim 3$ in satisfactory yields (59-71\%). The adsorption of these analogues on silica gel was largely reduced due to the presence of long fatty chains in the molecular structure. The structures of UA0 $\sim 3$ and their yields and physical appearances are shown in Table 2. UA0, which has no $\mathrm{C}=\mathrm{C}$ bond in the chain, is a light yellow solid, while UA1 $\sim 3$ appear as yellow liquids. Urushiol analogues are soluble in common organic solvents such as $\mathrm{CH}_{3} \mathrm{OH}, \mathrm{CHCl}_{3}$, and EtOAc, but insoluble in $\mathrm{H}_{2} \mathrm{O}$.

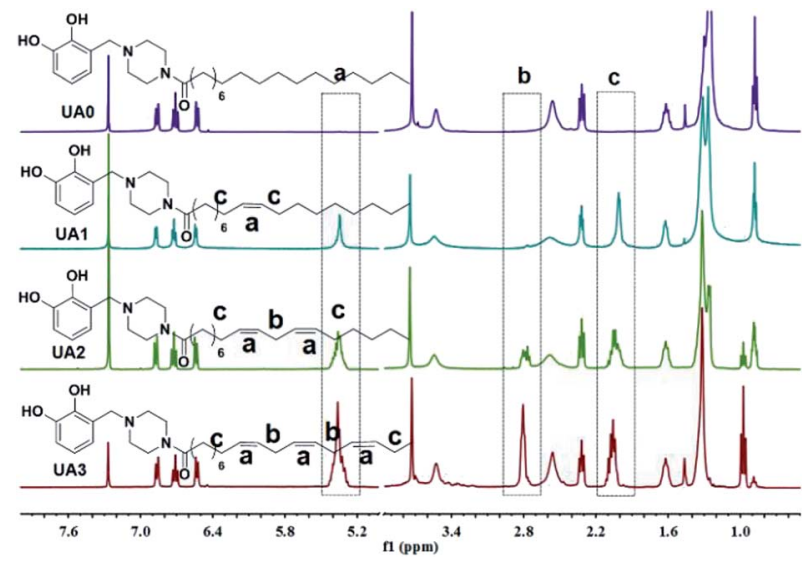

Fig. 1 Stacked ${ }^{1} \mathrm{H}$ NMR spectra of UAO $\sim 3$ for structural comparative analyses.

The structures of UA0 $\sim 3$ and their dissimilarities can be effectively determined using their stacked ${ }^{1} \mathrm{H}$ NMR spectra, as shown in Fig. 1. The identical aromatic resonances appear as a set of three signals of neighboring three Ar-Hs with $2: 3: 2$ splitting pattern in $\delta$ 6.5-7.0 ppm, representing the 3 substituted catechol unit of UA0 $\sim 3 .^{22}$ The difference in the UA0 $\sim 3$ spectra lies in the signals of the fatty chains; most evidently, UA0 has no signal but UA1 $\sim 3$ exhibit the vinylic hydrogen signal at $\delta 5.36 \mathrm{ppm}$, which increases in intensity with an increase in the number of $\mathrm{C}=\mathrm{C}$ bonds. Another distinction is that $\mathrm{UA} 2 \sim 3$ have the resonance of the methylene group flanked by $2 \mathrm{C}=\mathrm{C}$ bonds at $\delta 2.80 \mathrm{ppm}$, while UA1 has none, which only exhibits $\mathrm{C}=\mathrm{C}$-bond-neighboring methylene absorption at $2.06 \mathrm{ppm}$. Other characteristic resonances for UA0 $\sim 3$ are the peaks of the linking methylene $\left(\mathrm{N}-\mathrm{CH}_{2}\right)$ at $3.73 \mathrm{ppm}$, piperazine ring methylenes at 3.53 and $2.56 \mathrm{ppm}$, acyl methylene at $2.32 \mathrm{ppm}$, and the subsequent one at $1.62 \mathrm{ppm}$; the other methylenes in the chain are at $\sim 1.27 \mathrm{ppm}$. The terminal $-\mathrm{CH}_{3}$ of $\mathrm{UA} 0 \sim 2$ appears at $\delta 0.88 \mathrm{ppm}$, while the absorption occurs at $\delta 0.98 \mathrm{ppm}$ for UA3. It is worth mentioning that the ${ }^{1} \mathrm{H}$ NMR signal of the terminal $-\mathrm{CH}_{3}$ and its intensity can be used to

Table 2 Synthesis of urushiol analogues and their yields and physical appearances

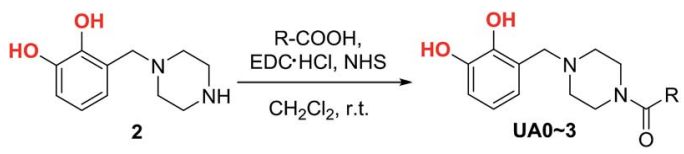

Compound


determine the purity of these commercial fatty acids, such that linoleic acid containing $25 \% \alpha$-linolenic acid and $\alpha$-linolenic acid having $10 \%$ linoleic acid can be directly calculated from their ${ }^{1} \mathrm{H}$ NMR spectra. The FTIR spectra of UA0 $\sim 3$ (Fig. S1†) provide no significant disparity but their common characteristic absorptions. For example, catecholic hydroxyls absorb at $3250 \mathrm{~cm}^{-1}$ as a broad peak, the amide group intensively appears at $1648 \mathrm{~cm}^{-1}$, and the vinylic $\mathrm{C}-\mathrm{H}$ bonds stretch at $3016 \mathrm{~cm}^{-1}$ with their intensity increasing with the number of $\mathrm{C}=\mathrm{C}$ bonds in the side chain, which is an important indicator to evidence their participation in the crosslinking reaction.

\section{Electropolymerization and its mechanism}

As mentioned in the Introduction section, laccase usually is ineffective in the polymerization of urushiol analogues due to its substrate specificity, which was also true in our case; hence, developing a curing approach was imperative. Here, UA0 $\sim 3$ were investigated for their electropolymerization on copper surfaces, as well as UAm and urushiol for effecting a comparison. They were first separately dissolved in ethanol containing $10 \%$ volumetric parts of $10 \mathrm{mM}$ Tris-HCl buffer $(\mathrm{pH} 8.5$; concentration: $30 \mathrm{mg} \mathrm{mL} \mathrm{mL}^{-1}$ ) and then cyclic voltammetry (CV) was applied with potential scanning from 0 to $3.0 \mathrm{~V} v$ s. SCE (Fig. 2a and S2 $\dagger$ ). An irreversible and broad oxidation peak within 1.0-1.9 V was observed for UA0 $\sim 3$ and UAm for the first scan cycle, as well as for urushiol, which can be attributed to the oxidation of the catechol unit. ${ }^{26}$ When compared with the analogues, urushiol exhibited a smaller oxidation peak at around $1.0 \mathrm{~V}$, reflecting that it is easier to be oxidized at the electrode and the available quantity is small. This is possibly due to the inferior solution stability of urushiol as compared to
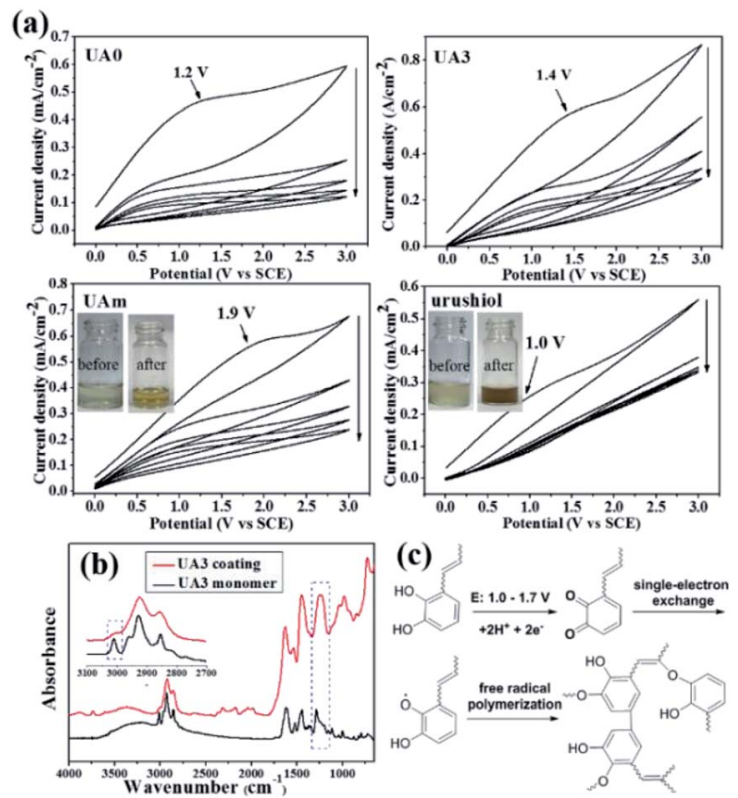

Fig. 2 CV plots of UAO, UA3, UAm, and urushiol, with potential scan cycles of $1,3,5,7$, and 9 , in the range of $0-3.0 \mathrm{~V}$ vs. SCE at a scan rate of $30 \mathrm{mV} \mathrm{s}^{-1}(\mathrm{a})$; ATR-FTIR spectra of UA3 and its coating (b); proposed mechanism for the electropolymerization of urushiol analogues (c). that of UA0 $\sim 3$ and UAm, which was observed by the color change in the solution during the solution preparation and electropolymerization process. The ethanol/Tris buffer solution of urushiol tended to quickly darken in about $10 \mathrm{~s}$, while the solutions of the analogues remained clear yellow, even when exposed to air (Fig. 2a: inset, UAm). During electropolymerization for about $1 \mathrm{~h}$, the urushiol solution became opaque and evolved to precipitate in the form of black particles (Fig. 2a; inset: urushiol), while the analogue solutions were still transparent and only turned claret red at the end. This can be attributed to the fact that most of the urushiol underwent a selfpolymerization reaction prior to reaching the electrode surface under the slightly basic condition of $\mathrm{pH} 8.5$, similar to that observed with dopamine that polymerizes under this $\mathrm{pH}$ condition in various applications. ${ }^{27}$ For the analogues in the solution, the analogous self-polymerization was considerably reduced, and their electropolymerization on the electrode became dominant, yielding a stronger oxidation peak. It is speculated that the analogues can form intramolecular hydrogen bonds between the phenolic hydroxyl and piperazine nitrogen (Fig. S3†), stabilizing the catechol ring and suppressing self-polymerization. With an increase in the number of scans, all the oxidation currents rapidly dropped; when the number of scan cycles was seven, the oxidation currents decreased to the minimum values and remained constant, suggesting that the formation of an insulating coating was a fast process.

The polymerization of these urushiol analogues and urushiol was also investigated by comparing their ATR-FTIR spectra before and after polymerization (Fig. S4†). As an example, the spectra of UA3 monomer and its coating are shown in Fig. $2 b$ for understanding. Before polymerization, UA3 exhibits the characteristic broad phenolic $\mathrm{O}-\mathrm{H}$ at around $3250 \mathrm{~cm}^{-1}$, Ar-H and alkenyl $=\mathrm{C}-\mathrm{H}$ at $3016 \mathrm{~cm}^{-1}$, strong saturated C-H absorption at about $2800-2980 \mathrm{~cm}^{-1}$, carbonyl at $1650 \mathrm{~cm}^{-1}$, phenyl ring band at about $1445 \mathrm{~cm}^{-1}$, and the phenylic $\mathrm{O}-\mathrm{H}$ bending at $\sim 1280 \mathrm{~cm}^{-1} \cdot{ }^{28}$ After polymerization, several variations in the spectrum are noticeable; for example, the significant decrease in $=\mathrm{C}-\mathrm{H}$ stretching at $3016 \mathrm{~cm}^{-1}$, combined enhancement of the phenyl ring band at about 1370$1520 \mathrm{~cm}^{-1}$, and the newly appeared strong bands at about 1236 and $976 \mathrm{~cm}^{-1}$. The decrease in the $=\mathrm{C}-\mathrm{H}$ stretching absorption can be attributed to the participation of $\mathrm{C}=\mathrm{C}$ bonds in the polymerization; the enhancement of the phenyl ring band may result from the coupling of phenyl rings, and the appearance of adsorptions at about 1236 and $976 \mathrm{~cm}^{-1}$ can be ascribed to the formation of aromatic ether bonds and trans $\mathrm{C}=\mathrm{C}$ bonds, respectively, in the polymerization. ${ }^{29}$

Taken together, the data of CV and FTIR, in combination with the mechanisms of urushiol evidenced by other methods, ${ }^{30,31}$ suggest that the analogue undergoes an electrochemically initiated radical polymerization process on the copper surface, which is shown in Fig. 2c. First, one catechol unit is anodically oxidized to its quinone form, which immediately reacts with another catechol unit to form a semiquinone radical species via a single-electron exchange; ${ }^{32}$ next, a variety of radical couplings occur, including those among the phenyl 

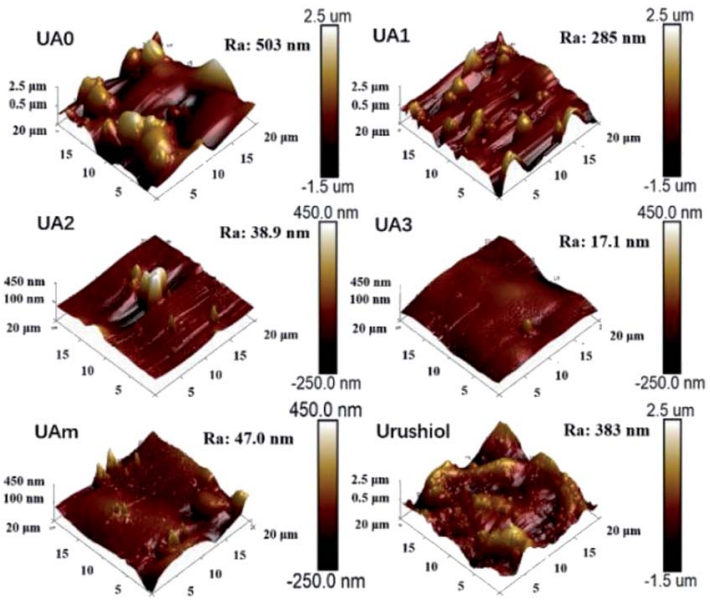

Fig. 3 AFM height images of $U A O \sim 3, U A m$, and urushiol coatings on copper.

rings, phenoxyl radical to phenyl ring and to the $\mathrm{C}=\mathrm{C}$ bond in the side chain, etc., leading to the formation of a complex crosslinking network. Overall, this electrochemical process involving urushiol analogues, at the stage of semiquinone radical formation, is similar to the electropolymerization of catechol-containing dopamine,$^{26}$ but slightly different to the curing processes of urushiol by laccase and UV irradiation, which are considered to directly generate the semiquinone radical. ${ }^{29}$ At the stage of free radical polymerization, the analogues react in a similar way as that of urushiol in the polymerization via laccase catalysis or UV irradiation. ${ }^{30,31}$

\section{Characterization of electropolymerization coatings}

The surface morphology of the electropolymerization coatings of UA0 $\sim 3$, UAm, and urushiol were characterized by AFM, as shown in Fig. 3, along with their values of average roughness $\left(R_{\mathrm{a}}\right)$. The surface of UA0 coating appears to have rugged and irregularly convex topology, where $R_{\mathrm{a}}=503 \mathrm{~nm}$. The UA1 surface is relatively flattened, where $R_{\mathrm{a}}=285 \mathrm{~nm}$. For the UA2 coating, its surface is flatter, exhibiting only a few large protrusions, where $R_{\mathrm{a}}=38.9 \mathrm{~nm}$. Interestingly, the topology of the UA3 coating is fairly smooth, without the existence of protrusions, and its $R_{\mathrm{a}}$ is very small $(17.1 \mathrm{~nm})$. UAm exhibits a relatively flat coating with small protrusions, where $R_{\mathrm{a}}=$ $47.0 \mathrm{~nm}$. In contrast, urushiol affords a coating surface with large and broad convex aggregates and $R_{\mathrm{a}}$ value as large as $383 \mathrm{~nm}$.

The differences in the morphologies of these coatings may arise from two aspects. The first is the influence of the molecular structure, which is clearly evident because the morphology of the coating has the flatness order of $\mathrm{UA} 0<\mathrm{UA} 1<\mathrm{UA} 2<\mathrm{UA} 3$, which is proportional to the number of $\mathrm{C}=\mathrm{C}$ bonds in the side chain; probably, the more the number of $\mathrm{C}=\mathrm{C}$ bonds in the side chain, the denser is the crosslinking network as well as increased suppression of the formation and aggregation of polymer particles. However, for UAm, the nature of the mixture favors the suppression of the crystalline aggregation, and therefore, afforded relatively flat topology. On the other hand, due to the instability of urushiol in the electrolyte solution, selfcrosslinking and subsequent aggregation accompanied the electropolymerization process of urushiol, leading to a highly rough surface of the coating, as shown in Fig. 3.

The physical properties of the coatings, such as the coating thickness, hardness, adhesion strength, water contact angle, and thermal stability, were also investigated, and the results are summarized in Table 3 . The coating thicknesses of UA0 $\sim 3$, as well as that of UAm, were between 12 and $15 \mu \mathrm{m}$, indicating that they underwent a crosslinking reaction at a similar rate in the electropolymerization process. In this aspect, urushiol behaved differently, yielding a coating with a thickness of only $7.5 \mu \mathrm{m}$. On the other hand, their coating hardness values varied dramatically, ranging from $1 \mathrm{H}$ to $6 \mathrm{H}$. For the urushiol coating, the highest hardness of $6 \mathrm{H}$ was determined, whereas the UA0, UA3, and UAm coatings exhibited a moderate hardness value of $4 \mathrm{H}$, and UA1 and UA2 coatings had a hardness value as low as 1H. Apparently, no positive correlation exists between the hardness and the number of $\mathrm{C}=\mathrm{C}$ bonds in the side chain. We ascribe this abnormal phenomenon to the complex process required to form coatings of urushiol and its analogues, as mentioned in the mechanism discussion. For example, UA0 has no $\mathrm{C}=\mathrm{C}$ bonds in the side chain and crosslinks only by means of the catechol itself, but it still yielded a moderately hard surface, probably arising from the strong interactions of the saturated alkyl side chains due to their regular orientation. ${ }^{33}$ It is noteworthy that the hardness of $4 \mathrm{H}$ (UA0, UA3, and UAm coatings) can be considered to be a good result, which is comparable to the hardness recently reported for organosilicone-cured urushiol coatings. ${ }^{34}$

All the coatings exhibited excellent adhesion strengths and high hydrophobicities. For example, the coatings of UA0 and urushiol have strength of $5 \mathrm{~B}$ and that of UA1 $\sim 3$ is $4 \mathrm{~B}$, which

Table 3 Physical properties and thermal stability of the electropolymerization coatings

\begin{tabular}{|c|c|c|c|c|c|c|c|c|}
\hline Coating & Thickness $(\mu \mathrm{m})$ & Pencil hardness & Adhesion strength & Contact angle $\left(^{\circ}\right)$ & $T_{10 \%}\left({ }^{\circ} \mathrm{C}\right)$ & $T_{50 \%}\left({ }^{\circ} \mathrm{C}\right)$ & $T_{\max }\left({ }^{\circ} \mathrm{C}\right)$ & $W_{\text {char }}(\%)$ \\
\hline UA0 & $11.7 \pm 1.8$ & $4 \mathrm{H}$ & $5 B$ & $114.1 \pm 1.5$ & 289.6 & 399.3 & 379.9 & 32.91 \\
\hline UA1 & $14.0 \pm 4.0$ & $1 \mathrm{H}$ & $4 \mathrm{~B}$ & $100.9 \pm 1.4$ & 284.5 & 445.0 & 423.7 & 39.84 \\
\hline UA2 & $15.6 \pm 2.8$ & $1 \mathrm{H}$ & $4 \mathrm{~B}$ & $94.7 \pm 0.5$ & 291.8 & 445.4 & 409.2 & 40.83 \\
\hline UA3 & $12.5 \pm 2.3$ & $4 \mathrm{H}$ & $4 \mathrm{~B}$ & $95.4 \pm 1.4$ & 284.1 & 457.6 & 401.6 & 44.29 \\
\hline UAm & $15.3 \pm 3.6$ & $4 \mathrm{H}$ & $4 \mathrm{~B}$ & $98.9 \pm 1.5$ & 286.1 & 456.7 & 379.9 & 44.66 \\
\hline Urushiol & $7.5 \pm 1.3$ & $6 \mathrm{H}$ & $5 \mathrm{~B}$ & $98.5 \pm 1.1$ & 321.8 & 446.5 & 437.2 & 34.62 \\
\hline
\end{tabular}


were measured with the standard ASTM D3359 test method. All the coatings were hydrophobic, with water contact angles ranging from $94.7^{\circ}$ to $114.1^{\circ}$. The thermal stability parameters of the coatings were obtained by TGA (Fig. S5 $\dagger$ ), including the weight loss temperatures $\left(T_{10 \%}\right.$ and $\left.T_{50 \%}\right)$, temperature of the maximum weight loss rate $\left(T_{\max }\right)$, and char yield at $600{ }^{\circ} \mathrm{C}$ $\left(W_{\text {char }}\right)$, and the results are listed in Table 3. All the individual coatings of the analogues and their mixture have similar $T_{10 \%}$ values $>280{ }^{\circ} \mathrm{C}$, which are slightly inferior to that of urushiol $\left(321.8^{\circ} \mathrm{C}\right)$. UA0 has a $T_{50 \%}$ value of $399.3{ }^{\circ} \mathrm{C}$, while UA1 $\sim 3$ have values $>440{ }^{\circ} \mathrm{C}$, similar to that of urushiol. All the $T_{\max }$ values for the analogues are around $400{ }^{\circ} \mathrm{C}$, somewhat lower than that of urushiol $\left(437.2^{\circ} \mathrm{C}\right)$. Except for the UA0 coating, one obvious advantage of the analogue coatings is their high $W_{\text {char values, }}$ much higher than urushiol, and the coatings of UA3 and UAm have $W_{\text {char }}$ values larger than $44 \%$, probably due to the higher number of $\mathrm{C}=\mathrm{C}$ bonds in the side chain. The abovementioned results reveal that these analogues and their mixture have high thermal stability.

\section{Anticorrosion performance of coatings}

The most fascinating properties of urushiol coatings are their high corrosion resistance and durability, which provides desirable protection for various materials, such as wood, ceramics, and metals. ${ }^{35}$ Copper is widely used in the industry and its corrosion protection is a longstanding interest. Therefore, the coatings of urushiol analogues were investigated for their protection toward copper, and the performance was compared with that of urushiol. The corrosion inhibition behavior was examined by potentiodynamic polarization, and the resulting Tafel curves of the $\mathrm{Cu}$ substrates with or without coatings in $3.5 \mathrm{wt} \% \mathrm{NaCl}$ solution are shown in Fig. $4 \mathrm{a}$. The corrosion current density $\left(i_{\text {corr }}\right)$ and potential $\left(E_{\text {corr }}\right)$ were obtained from the intersection of the cathodic and anodic Tafel curves using the Tafel extrapolation method, and the results are summarized in Table 4, along with the estimated corrosion rate (CR) and corrosion inhibition efficiency (IE).

Without any coating, the Cu substrate displayed an $i_{\text {corr }}$ value of $2.23 \times 10^{-5} \mathrm{~A} \mathrm{~cm}^{-2}$ and $E_{\text {corr }}$ at $-0.283 \mathrm{~V}$; for the newly prepared coatings, regardless of UA0 $\sim 3$, UAm, or urushiol, $i_{\text {corr }}$ significantly decreased by 3-4 orders of magnitude and $E_{\text {corr }}$ shifted to a higher positive potential by about $0.06 \mathrm{~V}$. Relatively, except the UA2 coating, which showed a slightly larger $i_{\text {corr }}$ value $\left(2.51 \times 10^{-8}\right)$, the other analogues, mixture, and urushiol, exhibited similar $i_{\text {corr }}$ values in the order of $10^{-9}$. The $\mathrm{Cu}$ substrates with these coatings were estimated to have CR values in the range of $10^{-4}$ to $10^{-5} \mathrm{~mm}$ per year, which are much less than those for bare copper. Based on the values of $i_{\text {corr }}$ and CR, excellent IE values up to $99.9 \%$ could be derived for the UA0 $\sim 3$ and UAm coatings, similar to the urushiol coating.

The long-term corrosion inhibitions of UA0 $\sim 3$ and UAm coatings on copper were also tested and compared with that of the urushiol coating (Fig. $4 \mathrm{~b}$ ). The test was performed on each coating on copper in the immersing solution of $3.5 \mathrm{wt} \% \mathrm{NaCl}$ with an interval of 1 week in a period of 4 weeks. The results at week 0 have been discussed above with respect to the freshly
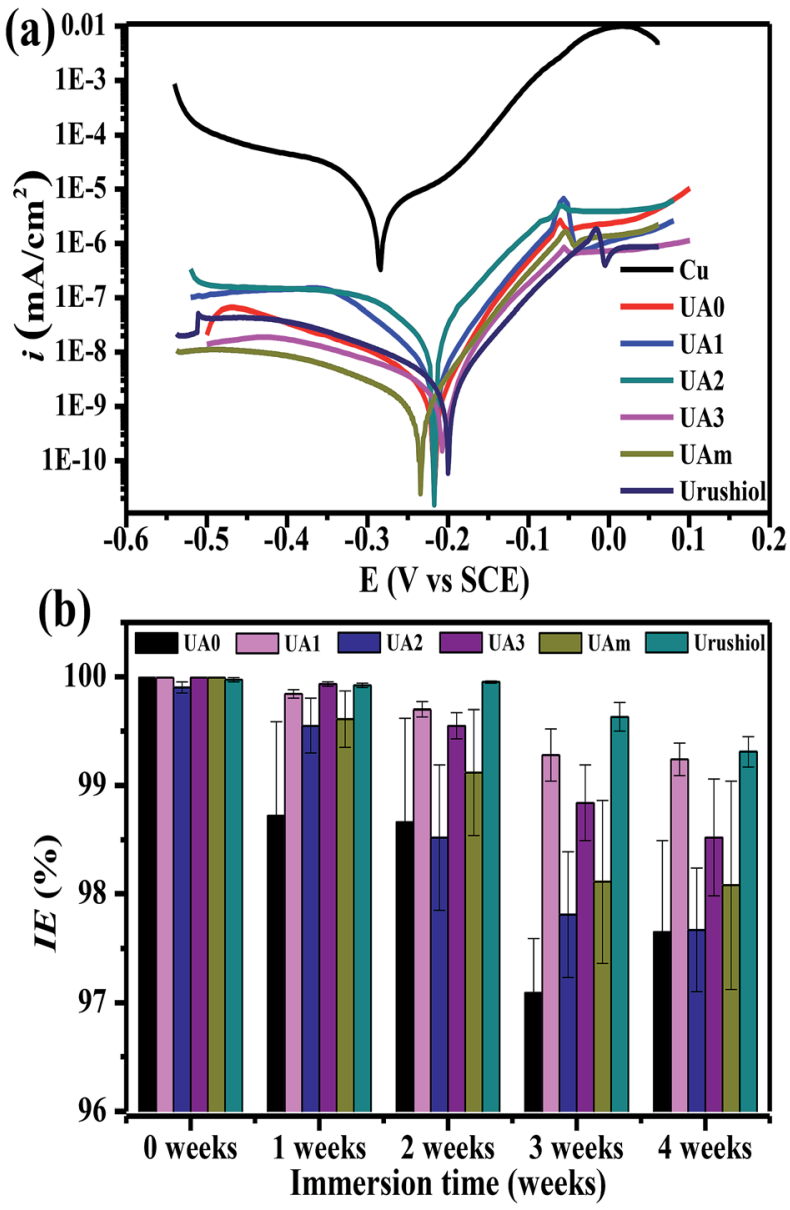

Fig. 4 Polarization curves of the $\mathrm{Cu}$ substrate without and with a coating in $3.5 \mathrm{wt} \% \mathrm{NaCl}$ solution at $25^{\circ} \mathrm{C}$ (a). Long-term corrosion inhibition performance of the UAO $\sim 3$, UAm, and urushiol coatings on copper in 3.5 wt\% $\mathrm{NaCl}$ (b).

prepared coatings. At week 1 , the effects of the UA0, UA2, and UAm coatings began to decrease, but still possessed IE values higher than $98 \%$; while for UA1, UA3, and urushiol, their coatings retained the similar excellent performance. With the passage of immersion time, all the coatings became slightly inferior to the original ones in inhibiting corrosion, but their IE values were still higher than $97 \%$; in particular, for UA1 and urushiol, the IE values of their coatings remained as high as $99 \%$. It should be noted that the long-term corrosion inhibition effects of these coatings are comparable to that of recently

Table 4 Corrosion data of copper with and without coatings

\begin{tabular}{lllll}
\hline & & $E_{\text {corr }}(\mathrm{V}$ \\
Sample & $i_{\text {corr }}\left(\mathrm{A} \mathrm{cm}^{-2}\right)$ & vs. SCE $)$ & CR $(\mathrm{mm}$ per year $)$ & IE $(\%)$ \\
\hline Copper & $2.23 \times 10^{-5}$ & -0.283 & $2.59 \times 10^{-1}$ & - \\
UA0 & $2.86 \times 10^{-9}$ & -0.216 & $3.32 \times 10^{-5}$ & 99.99 \\
UA1 & $4.42 \times 10^{-9}$ & -0.216 & $5.13 \times 10^{-5}$ & 99.99 \\
UA2 & $2.51 \times 10^{-8}$ & -0.213 & $2.91 \times 10^{-4}$ & 99.89 \\
UA3 & $2.01 \times 10^{-9}$ & -0.220 & $2.33 \times 10^{-5}$ & 99.99 \\
UAm & $9.44 \times 10^{-10}$ & -0.234 & $1.10 \times 10^{-5}$ & 99.99 \\
Urushiol & $2.50 \times 10^{-9}$ & -0.208 & $2.90 \times 10^{-5}$ & 99.99
\end{tabular}


reported graphene/lacquer composites. ${ }^{36}$ The desirable anticorrosion performance of urushiol analogues can be attributed to their ability to form a multiple crosslinking network, which prevents the corrosive species in the solution from coming into contact with the $\mathrm{Cu}$ surface. ${ }^{37}$

\section{Conclusions}

In this work, urushiol analogues with side chains of different number of $\mathrm{C}=\mathrm{C}$ bonds were designed and synthesized; the Mannich reaction of catechol with formaldehyde and $\mathrm{N}$-Bocpiperazine was exploited, which is a method that affords convenience, cost-effectiveness, and scalability in order to obtain urushiol analogues as an alternative to the resourcelimited and expensive natural urushiol. The electropolymerization of these analogues on copper was demonstrated to be practical in forming coatings on copper due to their higher aerobic stability than that of urushiol itself; this merit could be ascribed to the role of intramolecular hydrogen bonding. Importantly, the analogue coatings exhibited excellent corrosion inhibition performance on copper, as well as their longterm effect, which is crucial for applications involving copper in diverse fields. In addition, by analyzing the results using electrochemistry and ATR-FTIR characterization, a plausible mechanism for the electropolymerization of analogues on copper was proposed, which involves various free radical couplings occurring not just among the catecholic phenyl rings, but also the coupling of phenoxyl radical to phenyl ring and to $\mathrm{C}=\mathrm{C}$ bonds in the side chain. The developed synthesis strategy of urushiol analogues and the relevant electropolymerization method may have promising potential in the field of metal corrosion protection.

\section{Experimental}

\section{Reagents and compound analysis}

Catechol, $N$-Boc-piperazine, oleic acid (98\%), linoleic acid (98\%), and $\alpha$-linolenic acid (85\%) were purchased from Aladdin Reagent Co., Ltd. (China). 1-Ethyl-3-(3-dimethylaminopropyl) carbodiimide hydrochloride $(\mathrm{EDC} \cdot \mathrm{HCl}), \quad N$-hydroxysuccinimide (NHS), formaldehyde (37 wt\% aqueous), and stearic acid were obtained from Sinopharm Chemical Reagents Co., Ltd. (China). Other reagents and solvents were of the analytical grade and used without any further purification. Raw lacquer was obtained from the Institute of Lacquer (Xi'an, China). Urushiol was extracted from raw lacquer with ethanol. ${ }^{38}$ Ultrapure water $(18.2 \mathrm{M} \Omega \mathrm{cm})$ was prepared by a LabPure KLUP-UV-20 system (Kangning, China). The NMR spectra were recorded on a Varian NMR spectrometer (Mercury plus-400 or plus-600) using $\mathrm{CDCl}_{3}, \mathrm{CD}_{3} \mathrm{OD}$, or DMSO- $d_{6}$ as the solvent. Chemical shifts were reported in ppm relative to tetramethylsilane (TMS). The high-resolution ESI mass spectra were obtained on an Agilent 6530 accurate-mass Q-TOF spectrometer.

\section{Synthesis and isolation of 1-3 and 1-4}

A solvent $(60 \mathrm{~mL})$, formaldehyde $(3.24 \mathrm{~g}, 40 \mathrm{mmol}, 37 \mathrm{wt} \%$ aqueous), and $N$-Boc-piperazine ( $7.4 \mathrm{~g}, 40 \mathrm{mmol}$ ) were put in a round-bottom flask; after stirring at room temperature for 30 min under $\mathrm{N}_{2}$, catechol $(4.4 \mathrm{~g}, 40 \mathrm{mmol})$ was added. The reaction continued at a certain temperature for $4 \mathrm{~h}$. After removing $\mathrm{CH}_{3} \mathrm{OH}$, the resultant solution was adjusted to $\mathrm{pH} 2$ using dilute $\mathrm{HCl}$ and then extracted with EtOAc $(3 \times 100 \mathrm{~mL})$ to recover catechol. Subsequently, the aqueous phase was adjusted to $\mathrm{pH} 8$ with a dilute $\mathrm{NaOH}$ solution and then extracted with $5 \times$ $100 \mathrm{~mL}$ EtOAc. The combined organic phase was dried over anhydrous $\mathrm{Na}_{2} \mathrm{SO}_{4}$ and evaporated to afford a mixture. The mixture was dissolved in $\mathrm{CH}_{3} \mathrm{CN}$ and recrystallized to afford 14; while the filtrate was evaporated to yield a residue as 1-3. The obtained catechol, 1-3, and 1-4 were used to calculate the conversion rate of catechol and the yields of 1-3 and 1-4, as shown in Table 1.

For the purpose of structural characterization, the product mixtures of 1-3 and 1-4 obtained under nonoptimized conditions were subjected to purification on silica gel using petroleum ether/EtOAc (4/1, v/v) as the eluent, affording isolated 1-3 and 1-4.

3-((4-Bocpiperazin-1-yl)methyl)catechol (1-3). Yellow liquid. ${ }^{1} \mathrm{H}$ NMR (600 MHz, $\left.\mathrm{CDCl}_{3}, \mathrm{ppm}\right): \delta 6.87(\mathrm{~d}, J=7.9 \mathrm{~Hz}, 1 \mathrm{H}), 6.72$ $(\mathrm{s}, 1 \mathrm{H}), 6.54(\mathrm{~d}, J=7.6 \mathrm{~Hz}, 1 \mathrm{H}), 3.74(\mathrm{~s}, 2 \mathrm{H}), 2.56(\mathrm{~s}, 6 \mathrm{H}), 1.46$ (d, $J=1.0 \mathrm{~Hz}, 9 \mathrm{H}) .{ }^{13} \mathrm{C}$ NMR $\left(150 \mathrm{MHz}, \mathrm{DMSO}-d_{6}\right): \delta 156.1(\mathrm{~s}), 145.0$ (s), 142.9 (s), 124.7 (s), 121.6 (s), 121.5 (s), 80.7 (s), 59.4 (s), 50.6 (s), 44.0 (s), 27.9 (s). HRMS (ESI-TOF): calcd for $\left[\mathrm{C}_{16} \mathrm{H}_{24} \mathrm{~N}_{2} \mathrm{O}_{4}+\right.$ $\left.\mathrm{H}^{+}\right]$309.1819, found 309.1826.

4-((4-Bocpiperazin-1-yl)methyl)catechol (1-4). Yellow solid. ${ }^{1} \mathrm{H}$ NMR (600 MHz, $\left.\mathrm{CDCl}_{3}, \mathrm{ppm}\right): \delta 6.96(\mathrm{~d}, J=7.9 \mathrm{~Hz}, 1 \mathrm{H}), 6.76$ $(\mathrm{d}, J=7.9 \mathrm{~Hz}, 1 \mathrm{H}), 6.68(\mathrm{~d}, J=7.8 \mathrm{~Hz}, 1 \mathrm{H}), 3.74(\mathrm{~s}, 2 \mathrm{H}), 2.88-238$ $(\mathrm{m}, 6 \mathrm{H}), 1.46(\mathrm{~d}, J=1.0 \mathrm{~Hz}, 9 \mathrm{H}) .{ }^{13} \mathrm{C}$ NMR $\left(150 \mathrm{MHz}, \mathrm{DMSO}-d_{6}\right)$ : $\delta 157.1(\mathrm{~s}), 146.3(\mathrm{~s}), 144.1$ (s), 130.1 (s), $122.2(\mathrm{~s}), 116.5(\mathrm{~s}), 116.1$ (s), 81.8 (s), $64.4(\mathrm{~s}), 51.7$ (s), 45.0 (s), 28.9 (s). HRMS (ESI-TOF): calcd for $\left[\mathrm{C}_{16} \mathrm{H}_{24} \mathrm{~N}_{2} \mathrm{O}_{4}+\mathrm{H}^{+}\right]$309.1819, found 309.1828.

When the synthesis was conducted under optimized conditions $\left(\mathrm{CH}_{3} \mathrm{OH} / \mathrm{H}_{2} \mathrm{O}\right.$ in $1: 1$ volumetric ratio as the medium at $40{ }^{\circ} \mathrm{C}$ for $\left.4 \mathrm{~h}\right), 1-3$ was obtained in a yield of $76 \%$ (10.4 g) and 14 in a trace amount.

\section{Synthesis of 3-(piperazin-1-ylmethyl)catechol (2)}

A flask was charged with EtOAc (100 mL), 1-3 (6.16 g, $20 \mathrm{mmol})$, and concentrated $\mathrm{HCl}(37 \mathrm{wt} \%, 25 \mathrm{~mL})$, and the mixture was magnetically stirred for $4 \mathrm{~h}$ at room temperature. Thereafter, $50 \mathrm{~mL}$ water was added into the flask and the mixture was washed with EtOAc $(3 \times 100 \mathrm{~mL})$. Next, the aqueous phase was adjusted to $\mathrm{pH} 8$ with a dilute $\mathrm{NaOH}$ solution and extracted by EtOAc $(5 \times 100 \mathrm{~mL})$. The organic phases were combined, dried with anhydrous sodium sulfate, and concentrated by rotary evaporation to give a residue, which was recrystallized in $\mathrm{CH}_{3} \mathrm{CN}$ to give product 2 (3.99 g) as a yellow solid in a yield of $96 \%$.

3-(Piperazin-1-ylmethyl)catechol (2). ${ }^{1} \mathrm{H}$ NMR $(600 \mathrm{MHz}$, $\left.\mathrm{CD}_{3} \mathrm{OD}, \mathrm{ppm}\right): \delta 6.71(\mathrm{~d}, J=7.8 \mathrm{~Hz}, 1 \mathrm{H}), 6.59(\mathrm{t}, J=7.7 \mathrm{~Hz}, 1 \mathrm{H})$, $6.48(\mathrm{~d}, J=7.5 \mathrm{~Hz}, 1 \mathrm{H}), 3.65(\mathrm{t}, J=5.9 \mathrm{~Hz}, 2 \mathrm{H}), 3.61(\mathrm{~s}, 2 \mathrm{H}), 2.51$ 
$(\mathrm{t}, J=5.9 \mathrm{~Hz}, 10 \mathrm{H}) \cdot{ }^{13} \mathrm{C}$ NMR (150 MHz, DMSO- $\left.d_{6}\right): \delta 140.1(\mathrm{~s})$, 139.9 (s), 116.8 (s), 114.8 (s), 114.1 (s), 109.7 (s), 55.1 (s), 54.8 (s), $53.6(\mathrm{~s})$.

\section{Simplified procedure for the scale-up synthesis of 2}

A 4 -fold synthesis of 2 was carried out with a simplified procedure that combined the synthesis of 1-3 with the following hydrolysis. $\mathrm{CH}_{3} \mathrm{OH} /$ water (240 mL, $1: 1$ in volume), formaldehyde (12.96 g, $160 \mathrm{mmol}, 37 \mathrm{wt} \%$ aqueous), and $\mathrm{N}$-Bocpiperazine $(29.6 \mathrm{~g}, 160 \mathrm{mmol})$ were charged to a roundbottom flask; after stirring at room temperature for $30 \mathrm{~min}$ under $\mathrm{N}_{2}$, catechol $(17.6 \mathrm{~g}, 160 \mathrm{mmol}$ ) was added. The reaction continued at $40{ }^{\circ} \mathrm{C}$ for $4 \mathrm{~h}$. After removing $\mathrm{CH}_{3} \mathrm{OH}, 50 \mathrm{~mL}$ of $37 \% \mathrm{HCl}$ and $200 \mathrm{~mL}$ EtOAc were added, and the reaction mixture was stirred for $4 \mathrm{~h}$ at room temperature. The mixture was washed with EtOAc $(3 \times 200 \mathrm{~mL})$ and the aqueous phase was adjusted to $\mathrm{pH} 8$ with a dilute $\mathrm{NaOH}$ solution and extracted by EtOAc $(5 \times 200 \mathrm{~mL})$. The organic phases were combined, dried with anhydrous sodium sulfate, and concentrated by rotary evaporation to afford a residue, which was recrystallized in $\mathrm{CH}_{3} \mathrm{CN}$, yielding $24.3 \mathrm{~g}$ of 2 in a yield of $73 \%$.

\section{Synthesis of urushiol analogues (UAO $\sim 3)$}

General procedure. $\mathrm{EDC} \cdot \mathrm{HCl}(0.55 \mathrm{~g}, 2.9 \mathrm{mmol})$, fatty acid (2.4 mmol), and $\mathrm{CH}_{2} \mathrm{Cl}_{2}(50 \mathrm{~mL})$ were added to a round-bottom flask; after magnetic stirring at room temperature for $15 \mathrm{~min}$, the flask was cooled in an ice bath and NHS (0.39 g, $2.9 \mathrm{mmol})$ and $2(0.5 \mathrm{~g}, 2.4 \mathrm{mmol})$ was added. The reaction was heated to $40{ }^{\circ} \mathrm{C}$ overnight. After being evaporated to dry, the mixture was dissolved in EtOAc $(50 \mathrm{~mL})$, washed with a brine solution $(3 \times$ $30 \mathrm{~mL}$ ), dried with $\mathrm{Na}_{2} \mathrm{SO}_{4}$, and concentrated in vacuo to afford a residue. This residue was purified on silica gel using petroleum ether/EtOAc $(4 / 1, \mathrm{v} / \mathrm{v})$ as the eluent to give an urushiol analogue. The ${ }^{1} \mathrm{H}$ NMR spectra of UA0 $\sim 3$ are shown in Fig. S6. $\dagger$

3-((4-Stearoylpiperazin-1-yl)methyl)catechol (UA0). ${ }^{1} \mathrm{H}$ NMR $\left(400 \mathrm{MHz}, \mathrm{CDCl}_{3}, \mathrm{ppm}\right): \delta 6.88(\mathrm{~d}, J=7.9 \mathrm{~Hz}, 1 \mathrm{H}), 6.73(\mathrm{t}, J=$ $7.8 \mathrm{~Hz}, 1 \mathrm{H}), 6.55$ (d, J=7.4 Hz, 1H), $3.77(\mathrm{~s}, 2 \mathrm{H}), 3.57(\mathrm{~s}, 2 \mathrm{H})$, $2.62(\mathrm{~s}, 4 \mathrm{H}), 2.37-2.27(\mathrm{~m}, 2 \mathrm{H}), 1.67-1.55(\mathrm{~m}, 2 \mathrm{H}), 1.27$ (d, $J=$ $19.1 \mathrm{~Hz}, 29 \mathrm{H}), 0.88(\mathrm{t}, J=6.8 \mathrm{~Hz}, 3 \mathrm{H}) .{ }^{13} \mathrm{C} \mathrm{NMR}(100 \mathrm{MHz}$, $\left.\mathrm{CDCl}_{3}, \mathrm{ppm}\right): \delta 171.89(\mathrm{~s}), 144.78(\mathrm{~s}), 144.24(\mathrm{~s}), 120.60(\mathrm{~s})$, $119.88(\mathrm{~d}, J=2.0 \mathrm{~Hz}), 114.40(\mathrm{~s}), 61.19(\mathrm{~s}), 52.66(\mathrm{~d}, J=17.3 \mathrm{~Hz})$, $45.44(\mathrm{~s}), 41.40(\mathrm{~s}), 33.41(\mathrm{~s}), 32.04(\mathrm{~s}), 30.00-29.30(\mathrm{~m}), 28.51(\mathrm{~s})$, 25.43 (s), 22.81 (s), 14.25 (s), 0.12 (s). HRMS (ESI-TOF): calcd for $\left[\mathrm{C}_{29} \mathrm{H}_{50} \mathrm{~N}_{2} \mathrm{O}_{3}+\mathrm{H}^{+}\right]$475.3894, found 475.3889.

3-((4-Oleoylpiperazin-1-yl)methyl)catechol (UA1). ${ }^{1} \mathrm{H}$ NMR $\left(400 \mathrm{MHz}, \mathrm{CDCl}_{3}, \mathrm{ppm}\right): \delta 6.87(\mathrm{~d}, J=7.9 \mathrm{~Hz}, 1 \mathrm{H}), 6.72(\mathrm{t}, J=$ $7.8 \mathrm{~Hz}, 1 \mathrm{H}), 6.54(\mathrm{~d}, J=7.5 \mathrm{~Hz}, 1 \mathrm{H}), 5.45-5.27(\mathrm{~m}, 2 \mathrm{H}), 3.74(\mathrm{~s}$, $2 \mathrm{H}), 3.54(\mathrm{~s}, 3 \mathrm{H}), 2.58(\mathrm{~s}, 4 \mathrm{H}), 2.38-2.23(\mathrm{~m}, 2 \mathrm{H}), 2.01(\mathrm{~d}, J=$ $5.1 \mathrm{~Hz}, 4 \mathrm{H}), 1.62(\mathrm{~s}, 2 \mathrm{H}), 1.29(\mathrm{~d}, J=26.9 \mathrm{~Hz}, 20 \mathrm{H}), 0.88(\mathrm{t}, J=$ $7.0 \mathrm{~Hz}, 3 \mathrm{H}) .{ }^{13} \mathrm{C}$ NMR (100 MHz, $\left.\mathrm{CDCl}_{3}, \mathrm{ppm}\right): \delta 171.89(\mathrm{~s})$, 144.78 (s), $144.24(\mathrm{~s}), 120.60(\mathrm{~s}), 119.88$ (d, J=2.0 Hz), 114.40 (s), $61.19(\mathrm{~s}), 52.66$ (d, $J=17.3 \mathrm{~Hz}), 45.44(\mathrm{~s}), 41.40(\mathrm{~s}), 33.41(\mathrm{~s})$, $32.04(\mathrm{~s}), 30.00-29.30(\mathrm{~m}), 28.51$ (s), 25.43 (s), 22.81 (s), 14.25 (s), 0.12 (s). HRMS (ESI-TOF): calcd for $\left[\mathrm{C}_{29} \mathrm{H}_{48} \mathrm{~N}_{2} \mathrm{O}_{3}+\mathrm{H}^{+}\right] 473.3738$, found 473.3735 .
3-((4-Linoleoylpiperazin-1-yl)methyl)catechol (UA2). ${ }^{1} \mathrm{H}$ NMR $\left(400 \mathrm{MHz}, \mathrm{CDCl}_{3}, \mathrm{ppm}\right): \delta 6.87(\mathrm{~d}, J=7.9 \mathrm{~Hz}, 1 \mathrm{H}), 6.72(\mathrm{t}, J=$ $7.8 \mathrm{~Hz}, 1 \mathrm{H}), 6.54$ (d, $J=7.5 \mathrm{~Hz}, 1 \mathrm{H}), 5.46-5.26(\mathrm{~m}, 4 \mathrm{H}), 3.75$ (s, $3 \mathrm{H}), 3.54(\mathrm{~s}, 2 \mathrm{H}), 2.78(\mathrm{dd}, J=14.3,6.5 \mathrm{~Hz}, 2 \mathrm{H}), 2.59(\mathrm{~s}, 4 \mathrm{H})$, 2.37-2.25 (m, 3H), $2.04(\mathrm{dt}, J=15.5,7.7 \mathrm{~Hz}, 5 \mathrm{H}), 1.61$ (d, $J=$ $6.9 \mathrm{~Hz}, 3 \mathrm{H}), 1.38-1.19(\mathrm{~m}, 18 \mathrm{H}), 0.98$ (t, $J=7.5 \mathrm{~Hz}, 1 \mathrm{H}), 0.93-$ $0.81(\mathrm{~m}, 3 \mathrm{H}) .{ }^{13} \mathrm{C} \mathrm{NMR}\left(100 \mathrm{MHz}, \mathrm{CDCl}_{3}, \mathrm{ppm}\right): \delta 171.75(\mathrm{~s})$, 144.70 (s), 144.19 (s), 130.12 (d, $J=19.3 \mathrm{~Hz}), 129.73$ (s), 127.97 $(\mathrm{d}, J=15.1 \mathrm{~Hz}), 120.52(\mathrm{~s}), 119.73(\mathrm{~s}), 114.40(\mathrm{~s}), 61.04(\mathrm{~s}), 52.50$ $(\mathrm{d}, J=18.2 \mathrm{~Hz}), 45.29(\mathrm{~s}), 41.28(\mathrm{~s}), 33.26(\mathrm{~s}), 31.90(\mathrm{~s}), 31.52(\mathrm{~s})$, 30.02-28.89 (m), $27.20(\mathrm{~s}), 25.63(\mathrm{~s}), 25.28(\mathrm{~s}), 22.64(\mathrm{~d}, J=11.3$ $\mathrm{Hz}$ ), 14.15 (s). HRMS (ESI-TOF): calcd for $\left[\mathrm{C}_{29} \mathrm{H}_{46} \mathrm{~N}_{2} \mathrm{O}_{3}+\mathrm{H}^{+}\right]$ 471.3581 , found 471.3585 .

3-((4-Linolenylpiperazin-1-yl)methyl)catechol $\quad$ (UA3). ${ }^{1} \mathrm{H}$ NMR (400 MHz, $\left.\mathrm{CDCl}_{3}, \mathrm{ppm}\right): \delta 6.86(\mathrm{~d}, J=7.9 \mathrm{~Hz}, 1 \mathrm{H}), 6.71(\mathrm{t}, J$ $=7.8 \mathrm{~Hz}, 1 \mathrm{H}), 6.53(\mathrm{~d}, J=7.4 \mathrm{~Hz}, 1 \mathrm{H}), 5.41-5.29(\mathrm{~m}, 6 \mathrm{H}), 3.71(\mathrm{~d}$, $J=11.7 \mathrm{~Hz}, 3 \mathrm{H}), 3.53(\mathrm{~s}, 3 \mathrm{H}), 2.79$ (d, $J=14.3 \mathrm{~Hz}, 4 \mathrm{H}), 2.56(\mathrm{~s}$, $4 \mathrm{H}), 2.32(\mathrm{t}, J=7.6 \mathrm{~Hz}, 2 \mathrm{H}), 2.08(\mathrm{dt}, J=14.2,7.1 \mathrm{~Hz}, 4 \mathrm{H}), 1.62$ (s, 2H), 1.29 (d, $J=24.8 \mathrm{~Hz}, 10 \mathrm{H}), 0.95(\mathrm{dd}, J=24.7,17.2 \mathrm{~Hz}$, $3 \mathrm{H}) .{ }^{13} \mathrm{C} \mathrm{NMR}\left(100 \mathrm{MHz}, \mathrm{CDCl}_{3}, \mathrm{ppm}\right) \delta 171.82(\mathrm{~s}), 144.72(\mathrm{~s})$, 144.21 (s), 132.07 (s), 130.36 (s), 128.36 (d, J=5.3 Hz), 127.82 (s), 127.19 (s), 120.57 (s), 119.86 (s), 114.38 (s), 61.15 (s), 52.61 (d, $J=$ $17.7 \mathrm{~Hz}), 45.39$ (s), 41.37 (s), 33.38 (s), 29.48 (dd, $J=26.8,17.8$ $\mathrm{Hz}$ ), 27.30 (s), 25.67 (d, J=8.8 Hz), 25.37 (s), 20.66 (s), 14.42 (s). HRMS (ESI-TOF): calcd for $\left[\mathrm{C}_{29} \mathrm{H}_{46} \mathrm{~N}_{2} \mathrm{O}_{3}+\mathrm{H}^{+}\right] 469.3425$, found 469.3426 .

\section{Coating preparation}

$\mathrm{Cu}$ substrates $(>99.7 \%)$ were polished with emery papers, cut into square substrates in dimensions of $15.0 \times 10.0 \times 1.0 \mathrm{~mm}^{3}$, followed by washing ultrasonically with ultrapure water and ethanol for $5 \mathrm{~min}$. Next, the $\mathrm{Cu}$ substrates were ultrasonicated in diluted $\mathrm{HCl}$ for $10 \mathrm{~s}$, rinsed with water, and blow-dried with $\mathrm{N}_{2}$. An Autolab PGSTAT30 electrochemical workstation (Echo Chemie B.V., Netherlands) with a three-electrode system was used for the electropolymerization of $\mathrm{UAO} \sim 3$, where the $\mathrm{Cu}$ substrate was used as the working electrode, a saturated calomel electrode (SCE) as the reference electrode, and a platinum wire as the counter electrode. A solution of $10 \mathrm{mM}$ Tris$\mathrm{HCl}(\mathrm{pH}$ 8.5) diluted with ethanol (1: 10 in volume) containing one of the UA0 $\sim 3$ products in $30 \mathrm{mg} \mathrm{mL}^{-1}$ was used as the electrolyte. The analogue coating was formed by cyclic voltammetry with potential sweeping from 0 to $3.0 \mathrm{~V} v s$. SCE at the rate of $30 \mathrm{mV} \mathrm{s}^{-1}$ for 15 cycles. The coatings were rinsed with water and blow-dried for performance characterization.

A proportional mixture of UA0 $\sim 3$, denoted as UAm, consisting of the analogues UA0 (4.5 wt $\%)$, UA1 (15.0 wt\%), UA2 (10.8 wt\%), and UA3 (62.8 wt\%), was made according to the typical content of each 3-alkenyl catechol derivative in urushiol (Scheme 1a). UAm and natural urushiol were also electrodeposited on a $\mathrm{Cu}$ substrate for comparative analyses.

\section{Characterization of coatings}

The thickness of the coating was measured by a coating thickness gauge (EC-770, YUWESE, China); the pencil hardness was determined by the standard ASTM D3363 test method, and the 
adhesion strength of coating to copper was determined according to ASTM D3359. The static contact angle of a liquid droplet of water $(3 \mu \mathrm{L})$ on the coating was measured using the OCA 20 contact angle system (Dataphysics, Germany) and reported with the average value of 5 measurements on different sites. The ATR-FTIR was measured by a Nicolet iS10 spectrometer (Thermo Scientific, USA). The thermal stability of the coating was studied by thermogravimetric analysis (TGA 4000, PerkinElmer, USA) at a heating rate of $10{ }^{\circ} \mathrm{C} \min ^{-1}$ under constant $\mathrm{N}_{2}$ flow. The morphological images of the coatings on $\mathrm{Cu}$ were acquired using a MultiMode-8 SPM atomic force microscope system (AFM, Bruker) in the tapping mode and processed by the associated NanoScope Analysis software.

\section{Electrochemical corrosion measurements}

The anticorrosion performance of the coatings was characterized by potentiodynamic polarization ${ }^{39}$ with the electropolymerization system, where the coated $\mathrm{Cu}$ was used as the working electrode and a corrosive solution containing $3.5 \mathrm{wt} \%$ $\mathrm{NaCl}$ as the electrolyte. The potentiodynamic polarization curves were obtained by sweeping the potential from $-300 \mathrm{mV}$ to $+300 \mathrm{mV}$ relative to the open circuit potential (vs. SCE) at a scan rate of $1 \mathrm{mV} \mathrm{s}^{-1}$ at $25{ }^{\circ} \mathrm{C}$. For each measurement, three individual working electrodes without or with the same coating were measured to ensure reproducibility. The anticorrosion efficiency of the coating on copper was represented using its inhibition efficiency (IE), which was calculated according to the following equation:

$$
\operatorname{IE}(\%)=\left(i_{\operatorname{corr}(0)}-i_{\operatorname{corr}(\mathrm{c})}\right) / i_{\operatorname{corr}(0)} \times 100
$$

where $i_{\text {corr(0) }}$ and $i_{\text {corr(c) }}$ are the corrosion current densities in the absence and presence of a coating, respectively. The corrosion rate (CR) was calculated using the following equation:

$$
\mathrm{CR}=K\left(i_{\mathrm{corr}} / \rho\right) E_{\mathrm{w}}
$$

where $K$ is a conversion constant $\left(3.27 \times 10^{-3} \mathrm{~mm} \mathrm{~g}\right.$ per $\mu \mathrm{A}$ per $\mathrm{cm}$ per year), ${ }^{40} \rho=8.96 \mathrm{~g} \mathrm{~cm}^{-3}$ is the density of $\mathrm{Cu}, E_{\mathrm{w}}=$ 31.77 is the equivalent weight of $\mathrm{Cu}$.

\section{Conflicts of interest}

There are no conflicts to declare.

\section{Acknowledgements}

The authors gratefully acknowledge the financial supports from the National Natural Science Foundation of China (21772060), the Wuhan Municipal Front Program for Application Basis Research (2018010401011283), and the Central China Normal University Basic Research Fund of Education Ministry of China (CCNU18GF001).

\section{Notes and references}

1 S. Sato, R. Ido, T. Ose, Y. Takahashi, S. Kanehashi, T. Ishimura, T. Honda, T. Miyakoshi and K. Nagai, Prog. Org. Coat., 2017, 104, 43-49.

2 J. Saiz-Poseu, J. Mancebo-Aracil, F. Nador, F. Busqué and D. Ruiz-Molina, Angew. Chem., Int. Ed., 2019, 58, 696-714.

3 X. Zheng, J. Weng, S. Li, H. Liu, B. Hu, Y. Li, X. Meng and H. Ruan, Chem. Eng. J., 2014, 245, 265-275.

4 H. Watanabe, M. Takahashi, H. Kihara and M. Yoshida, Langmuir, 2019, 35, 4534-4539.

5 H. Jeong, J. Heo, B. Son, D. Choi, T. H. Park, M. Chang and J. Hong, ACS Appl. Mater. Interfaces, 2015, 7, 26117-26123.

6 G. Lligadas, A. Tüzün, J. C. Ronda, M. Galià and V. Cádiz, Polym. Chem., 2014, 5, 6636-6644.

7 X. Zheng, X. Xiong, J. Yang, D. Chen, R. Jian and L. Lin, Chem. Eng. J., 2018, 333, 153-161.

8 H. Langhals and D. Bathelt, Angew. Chem., Int. Ed., 2003, 42, 5676-5681.

9 H. Watanabe, A. Fujimoto, R. Yamamoto, J. Nishida, M. Kobayashi and A. Takahara, ACS Appl. Mater. Interfaces, 2014, 6, 3648-3653.

10 S. Kobayashi, Struct. Chem., 2017, 28, 461-474.

11 B. Loev and C. R. Dawson, J. Org. Chem., 1959, 24, 980-985.

12 L. Rong, K. Yukio and M. Tetsuo, Talanta, 2007, 71, 15361540.

13 S. Kobayashi, R. Ikeda, H. Oyabu, H. Tanaka and H. Uyama, Chem. Lett., 2000, 1-2.

$14 \mathrm{H}$. Watanabe, M. Takahashi, H. Kihara and M. Yoshida, ACS Appl. Bio Mater., 2018, 1, 808-813.

15 T. Tsujimoto, H. Uyama and S. Kobayashi, Macromolecules, 2004, 37, 1777-1782.

16 C. Zhou, Y. Hu, Z. Yang, T. Yuan, J. Huang, P. Li and Y. Liu, Prog. Org. Coat., 2018, 120, 240-251.

17 S. I. Shoda, H. Uyama, J. I. Kadokawa, S. Kimura and S. Kobayashi, Chem. Rev., 2016, 116, 2307-2413.

18 R. Ikeda, T. Tsujimoto, H. Tanaka, H. Oyabu, H. Uyama and S. Kobayashi, Proc. Jpn. Acad., 2000, 76, 155-160.

19 R. Ikeda, H. Tanaka, H. Uyama and S. Kobayashi, Polym. J., 2000, 32, 589-593.

20 F. Gao, W. G. Zhang, G. C. Shen and J. Y. Tang, Journal of Fujian Teachers University (Natural Science), 2003, 1, 017.

21 R. Yue, H. Huang, G. Ke, H. Zhang, J. Pei, G. Xue and G. Yuan, Mater. Charact., 2017, 134, 114-122.

22 J. Duan, W. Wu, Z. Wei, D. Zhu, H. Tu and A. Zhang, Green Chem., 2018, 20, 912-920.

23 T. Yurino, Y. Aota, D. Asakawa, T. Kano and K. Maruoka, Tetrahedron, 2016, 72, 3687-3700.

24 J. B. Grosse Daldrup, C. Held, G. Sadowski and G. Schembecker, Ind. Eng. Chem. Res., 2011, 50, 3503-3509.

25 O. Fraczak, A. Lasota, D. Tymecka, P. Kosson, A. Muchowska, A. Misicka and A. Olma, J. Pept. Sci., 2016, 22, 222-227.

26 J. Yang, M. A. Cohen Stuart and M. Kamperman, Chem. Soc. Rev., 2014, 43, 8271-8298. 
27 X. Du, L. Li, F. Behboodi-Sadabad, A. Welle, J. Li, S. Heissler, H. Zhang, N. Plumeré and P. A. Levkin, Polym. Chem., 2017, 8, 2145-2151.

28 C. Narita, K. Yamada and T. Tsujii, Mater. Chem. Phys., 2017, 199, 387-392.

29 J. Xia, J. Lin, Y. Xu and Q. Chen, ACS Appl. Mater. Interfaces, 2011, 3, 482-489.

30 J. Yang, F. Shen, J. Deng, J. Cai, Q. Zhang and W. Liu, J. Appl. Polym. Sci., 2018, 135, 1-8.

31 X. L. Zheng, J. B. Weng, Q. M. Huang, B. H. Hu, T. Qiao and P. Deng, Colloids Surf., A, 2009, 337, 15-20.

32 C. Zhang, M. Q. Ma, T. T. Chen, H. Zhang, D. F. Hu, B. H. Wu, J. Ji and Z. K. Xu, ACS Appl. Mater. Interfaces, 2017, 9, 34356-34366.

33 H. Watanabe, A. Fujimoto, J. Nishida, T. Ohishi and A. Takahara, Langmuir, 2016, 32, 4619-4623.
34 Y. Deng, W. Bai, X. Zhang, J. Chen, S. Wang, J. Lin and Y. Xu, ACS Omega, 2018, 3, 4129-4140.

35 H. P. Wang, Q. Wu, C. M. Li and N. Gu, Mater. Corros., 2013, 64, 347-352.

36 Y. Deng, W. Bai, J. Chen, X. Zhang, S. Wang, J. Lin and Y. Xu, RSC Adv., 2017, 7, 45034-45044.

37 N. C. Rosero-Navarro, S. A. Pellice, A. Durán, S. Ceré and M. Aparicio, J. Sol-Gel Sci. Technol., 2009, 52, 31-40.

38 A. Yağan, N. Ö. Pekmez and A. Yildiz, Corros. Sci., 2007, 49, 2905-2919.

39 J. Chen, W. Cheng, S. Chen, W. Xu, J. Lin, H. Liu and Q. Chen, Nanoscale, 2018, 10, 22818-22829.

40 Z. Wei, X. Chen, J. Duan, G. Zhan, Y. Wei and A. Zhang, J. Mol. Liq., 2019, 280, 327-333. 